\title{
Human Learning: implicit and explicit
}

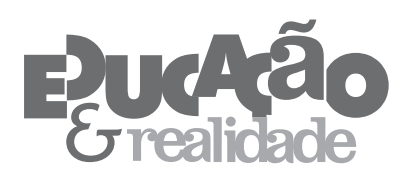

\author{
Peter Jarvis' \\ 'University of Surrey, Guildford, Surrey - United Kingdom
}

\begin{abstract}
Human Learning: implicit and explicit. Building on Polanyi's insight in The Tacit Dimension that we know more than we can tell, this paper argues that we actually experience more of reality than that of which we are conscious. Our conscious experience becomes the basis of explicit learning but that which we experience but of which we are not conscious is the basis of implicit learning and tacit knowledge.

Keywords: Human Learning. Implicit Learning. Explicit Learning. Tacit Knowledge. Conscious Experience.
\end{abstract}

RESUMO - Aprendizagem Humana: implícita e explícita. Com base na visão de Polanyi em sua obra A Dimensão Tácita, na qual ele afirma que nosso conhecimento vai além do que conseguimos expressar, este artigo argumenta que realmente experienciamos mais da realidade do que estamos conscientes. Nossa experiência consciente torna-se a base da aprendizagem explícita, porém o que experienciamos sem estarmos conscientes, é a base da aprendizagem implícita e do conhecimento tácito.

Palavras-chave: Aprendizagem Humana. Aprendizagem Implícita. Aprendizagem Explícita. Conhecimento Tácito. Experiência Consciente.

Educação \& Realidade, Porto Alegre, v. 40, n. 3, p. 809-823, July/Sept. 2015 809 http://dx.doi.org/10.1590/2175-623648387 
Human Learning

As my writing no doubt demonstrates, I have been fascinated by the complex processes of human learning for much of my academic life and despite all that I have written about it, I have always realised that my work was not really reaching some of the more complex areas, and so in this presentation I want to proceed a little further along this quest and explore the fundamental differences between explicit and implicit learning. The paper will begin with two experiences that I have had which set the scene; the second part will examine explicit learning, and in this it will reflect and summarise some of my previous thinking but take it a little further; the third section contrasts this with the two experiences that I recorded in the first section and examines implicit learning; the final section consists of some reflections about the differences between these two forms of learning and their implications.

\section{Part 1: my experiences}

I want to start this address by telling you two different stories about learning - they are both true and both happened to me in Japan: one about twenty years ago and the other two years ago. Thereafter we will analyse both experiences and then seek to draw some speculative conclusions about the nature of human learning.

Experience 1: I was travelling with a Canadian scholar and we were met from the train in the city of Fukuoka by a Japanese professor - we got into his car and he drove us to our hotel. In this instance I was sitting in the front seat with the driver. After we had checked in at the hotel, we left our keys at the reception and we were taken into the city. After an hour or so, our host had to excuse himself as he had a meeting to attend. He took us to the railway station and told us - the hotel was just four stations on that specific line. OK - we had no problems at the time and after a meal we went and purchased our tickets, got on the train and went out four stations: then the problems began - we did not read Japanese! We were not sure which was the main exit and so we followed the crowds. But the problem was compounded because when we reached the main road, we did not know where our hotel was - nor did we know its name because we had left our keys at the reception! We could not ask anybody - we did not know where to ask for! We walked up and down the side roads for about 45 minutes and then, suddenly, standing in the middle of the road at a junction - I knew where the hotel was and said to my companion if we go down this road, there is a dog-leg turning and the hotel is directly beyond it on the right-hand side. We walked to the dog-leg and sure enough the hotel was there - but how do I know? I did not know - the next morning we retraced our steps and began asking how I knew - and then it dawned on me - when we were brought there the previous day I was sitting in the front seat of the car, but in the evening I was standing in the middle of the road - in both instances I experienced almost precisely the same picture (sensation) - but I could only recall the first because I was there the second time. 
Now the question is - had I learned the route the first time? You could say that I had but I was not conscious of it. I called it pre-conscious learning in my earlier studies (Jarvis, 1987). But - did I need to be conscious of it for it to have been learning or had I learned it and not been aware of it? The point is I was not aware of my 'knowledge' before I became conscious of it - this is the point of consciousness - self-awareness when I was standing in the road and pointing in the direction of the hotel.

Experience 2: Two years ago when I was in Kyoto I visited two places in one afternoon and had similar experiences - first we went to a large store where two elderly men were working, weaving a massive and beautiful piece of silk. They were working together with many strands of silk thread producing this beautiful product. It was all very complicated and I requested the students to ask the weavers how long it had taken them to learn to do their work - they said that is was about ten years. Later that afternoon Yoko and Muchi took me to a tea rooms where we watched a chef perform his art and enjoyed some tea and cakes - we asked him the same question and got the same answer - about ten years.

But I wonder if we had been able to ask them about the knowledge they had to produce the product that they were producing, whether we would have got a satisfying answer - I doubt it.

This last example suggests that expertise does not come in a short period of time - 'ten years' was what the weavers and the chef told me that it took to acquire their expertise. All the research on expertise points us to the idea that it takes about 10,000 hours of practice to become an expert (Gladwell, 2005; Ericsson, 2009; Sennett, 2008; inter alia). But this does not mean that there was just a mindless repetition of procedures, but rather - as Nyiri suggests below - a constant interaction between the actors and external reality in trying to produce a better product and in the process the workers' actual action itself undergoes some slight changes from time to time, but the actors are not always conscious of it. The action may be, on some occasions, an unconscious adaptation of the behaviour in order to respond to the external pressures.

However, if we were in a position to ask master craftsmen about their theory of practice, they might not describe precisely what they were doing, as Nyiri suggests and as Argyris and Schon (1974) discovered when they started their work on professional practice. They distinguished between espoused theories and theories-in- use - the one explicit and the other implicit, but they (1974, p. 12) also go on to make the following important point:

Professionals and professional educators - indeed, practitioners of all sorts - often speak of practicing and learning skills as though those activities were an entirely different sort than learning a theory and learning to apply a theory. This viewpoint suggests that skill learning and theory learning are different kinds of activities; it suggests fur- 
ther that theory learning may be appropriately undertaken in one kind of place (school) and skill learning in another (work) (Argyris; Schon, 1974).

Espoused theory is explicit knowledge whereas theory-in-use is implicit: that is that the knowledge involved in performing the action is tacit. But significantly they suggest that learning tacit knowledge may be a different process from learning espoused or explicit, knowledge, which is precisely what Archer (2000, p. 143), commenting on the work of the neuroscientist - Stephen Rose - suggests:

\begin{abstract}
Procedural memories, unlike declarative, do not seem to be forgotten in the same way, suggesting that they are both learned and remembered by a very different mechanism from declarative ones. Perhaps this is because memories that involve procedural rather than declarative modes - such as riding a bicycle - are not confined simply to the brain but involves whole sets of other bodily memories, encoded in muscles and sinews (Archer, 2000).
\end{abstract}

Fundamentally, we can see that there may be major differences between these two types of learning but traditionally, we have accepted that all our learning is from conscious experience.

\title{
Part 2: explicit learning
}

This section will contain two distinct elements: the nature of the learning process and the content of the experience from which we learn.

The Nature of the Learning Process: Learning as a distinct and discrete phenomenon for study has really only come to the fore in the past half century. Originally, learning was seen as a feature of teaching, 'I will learn you!' Thereafter it was regarded as an outcome of teaching and more recently it was recognised as a part of the process of growth and development, but now it is beginning to be recognised as an intrinsic function of consciousness or even of living itself. Learning is both life long and life wide, but it need not be part of an educational process; indeed, it probably occurs much more frequently in situations other than the educational context within which it has so often been employed. It is hard to think of a living organism which does not learn, or respond to external forces, in one way or another. Indeed, Illeris (2007, p. 3; 2009, p. 7) has tried to capture this in his definition of learning: 'any process that in living organisms leads to permanent capacity change and which is not solely due to biological maturation or ageing'. His exceptions are both debatable although this is not the place to discuss them.

In my own work, I have also tried to offer a very broad definition of human learning which seeks to capture the contentious nature of the person: 
The combination of processes throughout a lifetime whereby the whole person - body (genetic, physical and biological) and mind (knowledge, skills, attitudes, values, emotions, meaning, beliefs and senses) - experiences natural and social situations, the content of which is then transformed cognitively, emotively or practically (or through any combination) and integrated into the individual person's biography resulting in a continually changing (or more experienced) person (Jarvis, 2009, p. $35)^{1}$.

I have depicted these processes in the following diagram:

Figure 1 - The Transformation of the Person through Learning

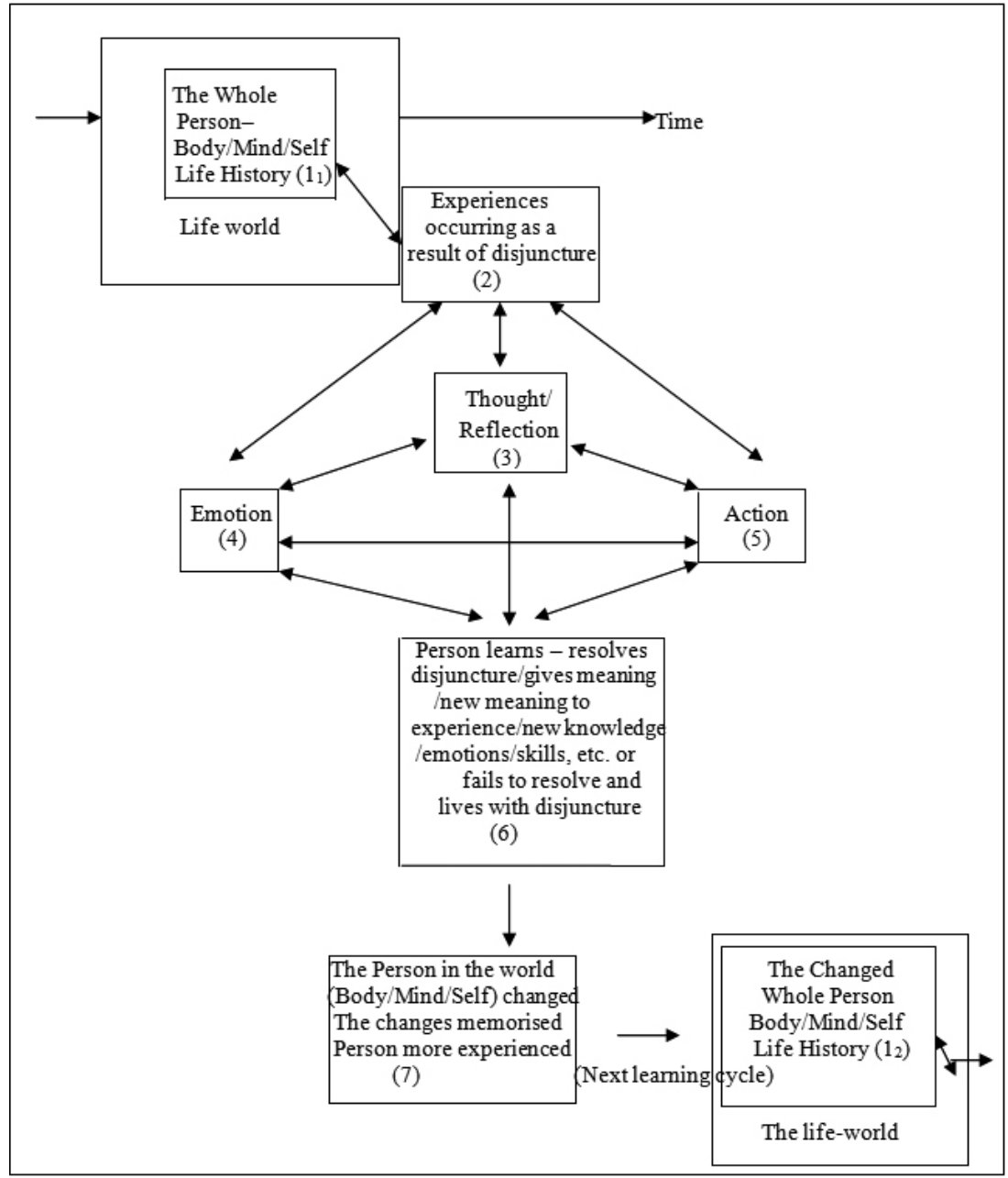

Source: author. 
Human Learning

Box $1_{1}$ depicts the situation of people in their life-world but this diagram only reflects a single period of time and the arrow (from box 1) depicts the movement throughout life when we journey from one life-world to another. However, for much of our time we live in a taken-for-granted situation in which we perform almost unthinkingly similar and repetitive actions, until such time as a situation causes us to question this taken-for-grantedness, often because our life-world has changed as we change our life situation. It is in both the social and natural situations that people experience disjuncture (box 1). This state can occur when people are alone, reflect on previous events, or even when they have an experience in interacting with the natural world, so that not all disjunctural experiences occur as a result of language and interaction as some social constructivists hold (see Archer, 2000, p. 86117). The state of disjuncture occurs when we can no longer presume upon our world and act upon it in an almost unthinking manner; it is at this point that we have an experience (Box 2,) and it need not be contained within the bounds of language. Indeed, it can and does precede language in small children and in inexplicable situations (Jarvis, 1987; 1997). However, there has been a tendency in my work - and also I believe in other scholars - to restrict the experience to the conscious experience, or to the part of the phenomenon about which we are paying attention, rather than recognising that we actually perceive the whole situation, some of it less consciously than others. This is significant because we are, therefore, learning from a wider experience than that of which we are conscious and through other senses than those which we are aware we are using.

Our experience can be transformed by thought, emotion or action (Boxes 3-5), or any combination of them. Box 6 is included to underline the fact that the outcome of the transformation is that people actually learn or fail to resolve their disjuncture, but this process itself always results in a changed person, even when there is apparently no learning since the experience still affects the self of the learner (Box 7). When people fail to resolve their disjuncture they can either learn to live in ignorance or with an awareness that they need to learn in order to resolve their disjuncture or they can start the whole process off again. It is necessary to note that boxes 3 and 4 cannot really be separated since thoughts and feelings nearly always accompany each and when we examine 'doing' (box 5) it almost always incorporates boxes 3 and 4 .

Many theorists of learning, including myself, have until recently focused their studies on learning to know: this is perhaps natural because all sense experiences apparently have a cognitive element, as Oakeshott (1933, p. 19) has reminded us: all sensations imply 'consciousness, consciousness implies judgement, and judgement is thought'. Conscious learning is a way of knowing and within the educational context it is not only the most common but has been almost the only way that is accepted until recently when it was recognised that there are other 
sites of learning, such as the work-place. As so much has been written about conscious learning (see Jarvis, 2006; 2009; Illeris, 2009, inter alia) I do not intend to rehearse a great deal of it here but I do want to focus on the concept of consciousness. Consciousness is a very problematic concept about which many volumes have been written (Chalmers, 1996; Dainton, 2000; Dennett, 1969; Feser, 2005; Rose, 2006, inter alia) with authors taking a variety of perspectives; from Dennett who argues that only objective evidence should be acceptable in the philosophy of mind to Chalmers who suggests that there are two forms of consciousness phenomenological and psychological. Dainton, on the other hand, asks whether matter can possess some little degree of consciousness - this is a possibility that Sheldrake (2012) does not rule out completely. Rose's position is closer to Dennett's while Feser is closer to Chalmers.

Conscious experience occurs at every disjuncture in life and our experiences occur through all of the senses. Chalmers (1996, p. 6-11) provides a non-philosophical and incomplete list of types of conscious experience: visual, auditory, tactile, olfactory, taste, experiences of hot and cold, pain, other bodily sensations, mental imagery, conscious thought, emotions and the sense of self. He points out that this list omits many other forms of experience, such as desire, day-dreaming, and neither does it discuss combinations such as taste and smell, and so on. Every facet of consciousness is experiential and it is from the conscious experiences that we learn - we learn from the act of living.

The Content of Experience: When we have a conscious experience we focus our awareness (Marton; Booth, 1997) on an aspect or more of our immediate external reality and we internalise our perceptions of that social reality. However, it is necessary to recognise that our awareness of events or happenings in our life (whether intended or otherwise) is usually incomplete because our minds have not taken a photograph of the event nor our memories a recording of the happenings, but rather we are aware of that part of external reality upon which we have focused our minds.

In our focusing our attention we search that reality for significant elements and, as Mary Archer (2000, p. 141) says in citing the neuroscientist Steven Rose, that we select these key features that are relevant to us. By so doing we are constructing our own reality as a result of our previous experiences and our perception of what we are experiencing, although we are not always consciously aware that we are making this selection. Ever since the work of Berger and Luckmann (1966) many social scientists have accepted the idea that the representation that we have internally of the external world is a social construction rather than a mirror image, but Freud has taught us that this construction is often not as rational as perhaps we would like it to be since we see and hear only what we want to. But neither does that representation have sharply defined boundaries so that we could claim, for instance, that this bit 
Human Learning

of external reality has been internalised and that bit just beyond the boundary has not; since it is a representation rather than anything else there are aspects of the event or happening that lie at the periphery of our conscious experience of which we are not consciously aware but these may often get internalised unconsciously at the same time as the phenomena of which we are consciously aware. This is a point that is hard to demonstrate but there is circumstantial evidence, as we will see below, and also from my first example above ${ }^{2}$.

It is clear that from this that what we internalise is more than that which we are consciously aware but neither are we consciously aware that we are constructing our perception rather than recording it internally: it is this difference between what we have consciously internalised and what we may have actually internalised that is significant for our understanding of implicit learning: It is our perception of that internal reality which is transformed in the learning process by our thinking, feeling and doing - as the above diagram suggests - and this process is explicit. We are consciously aware of our learning in all three dimensions, but it is that unconscious internalisation which we have often forgotten but which is also very important to us.

\section{Part 3: implicit learning}

What we have seen in the above discussion that our experience is broader than our conscious awareness of it and implicit learning is always reactive learning since pro-action requires consciousness awareness and implicit learning, by definition, does not require it. Implicit learning may be defined as 'learning that takes place largely independent of awareness of both the process and acquisition and the content of the knowledge so acquired' (Reber, 1985, p. 392). Knowledge acquired in this fashion is sometimes called procedural knowledge because it is frequently knowledge about doing. It many ways it relates to very similar terms incidental learning and latent learning but we shall use only the term implicit and relate it to our earlier discussion on conscious learning. In order to understand how we learn implicitly it is necessary to recognise that our awareness of events or happenings in our life (whether intended or otherwise) is usually incomplete because our minds have not taken a photograph of the event nor our memories a recording of the happenings, but rather than having a representation of the external we have an internally constructed image of the event which is based upon our awareness and perception of what has occurred. Since it is a perception rather than anything else there are aspects of the event or happening that lie at the periphery of our conscious experience of which we are not consciously aware and these probably get internalised unconsciously at the same time as the phenomenon on which our conscious awareness has focused. In addition we internalise our affective reaction to these experiences unconsciously and our personal

816 Educação \& Realidade, Porto Alegre, v. 40, n. 3, p. 809-823, July/Sept. 2015. 
values and attitudes to life emerge out of such situations. Indeed, even our identity is moulded in part by our implicit learning in everyday life. Damasio (2000, p. 36) suggests that 'there is no evidence to suggest that we are conscious of our feelings' but our internal and private feelings underlie our emotions which are outward and public. The point is that our total experience - conscious and unconscious - is always broader than our conscious awareness of it and it is from this that lies beyond the conscious that we learn implicitly - it is something that comes from our senses and is internalised beyond our conscious awareness: and learned through our senses and while we have many examples of this we have not yet a great deal of research on this aspect of learning, but it does lead to us knowing more than we are aware that we know - which is one of the points that Polanyi (1967) made about tacit knowledge.

Baumard (1999, p. 56) in commenting on this lack of research says that in its first five decades implicit learning was a phenomenon of language and the laboratory - it certainly made little impression on our understanding of learning, per se. However, in studies of decision making, it was recognised that this is an important aspect and, as Baumard points out, our understanding of this phenomenon is very important if we are going to understand motivation.

It was a number years before that Nyiri (1988, p. 20-21), writing about expertise, wrote:

\begin{abstract}
One becomes an expert not simply by absorbing explicit knowledge of the type found in text-books, but through experience, that is, through repeated trials, 'failing, succeeding, wasting time and effort... getting a feel for the problem, learning when to go by the book and when to break the rules'. Human experts gradually absorb 'a repertory of working rules of thumb, or 'heuristics', that combined with book knowledge, make them expert practitioners. This practical, heuristic knowledge, as attempts to simulate it on the machine have shown, is 'hardest to get at because experts - or anyone else - rarely have the self-awareness to recognize what it is. So it must be mined out of their heads painstakingly, one jewel at a time (Feigenbaum; McCorduck, 1984 apud Nyiri, 1988, p. 20-21).
\end{abstract}

Basically, Nyiri was arguing that experts are able to produce something beautiful/really nice to taste, and so on, but that the knowledge they use to do it is not readily available in their conscious minds. Similarly, Baumard (1999, p. 23) records how a Japanese corporation sought to discover the art of bread-making from a master baker at the Osaka International Hotel where the baker had a really good reputation, but it realised that it might not be possible to mine the jewels one at a time because the master bread maker might not be able to articulate his knowledge of his skill. Consequently, one of a development team involved in making bread-making machines and seeking to learn from 
this master baker apprenticed herself to work along side him and learn both by doing and by careful observation ${ }^{3}$. The baker's knowledge, if it may be described as that was procedural knowledge - tacit knowledge - learned perhaps in a different manner to conscious knowledge, and it was this that the researcher endeavoured to discover and record and when the research was complete the company was able to incorporate elements of the master craftsman's technique successfully into the new machine and market it successfully.

A great deal of implicit learning occurs in the ordinary process of living since we continually perceive sensations through our senses and we are not always aware of but there is an increasing amount of research carried out in the areas of biographical learning (see Alheit, 2012; Alheit et al., 1995). Alheit (2012, p. 172) points out that:

Through implicit learning processes that operate from the beginning of one's life, both inside and outside of institutions, we not only appropriate single experiential elements as components of the social world, but we develop the 'appropriation system' itself.

This unconscious learning is a state that occurs just beyond awareness and yet it is a very common way of knowing. Many experiments have demonstrated how subliminal advertising influences people's behaviour and causes them to purchase the advertised product, and so forth. Wexler (2006), however, also demonstrates how our having familiarity with phenomena affect our future behaviour even though we are not aware of the initial process of becoming familiar. For instance, he $(2006$, p. 158) records an experiment where the same set of Turkish words were printed in two American college newspapers daily for a number of weeks - no explanation was given for the appearance of the words. Then students were sent questionnaires and among the questions was one containing a number of Turkish words and the students were asked indicate the words that they liked better and the students all chose the words that appeared in the newspaper most frequently. Wexler (2006, p. 159) writes that as an individual becomes familiar with an object 'its neural representation becomes more developed and more easily activated by subsequent exposures to that object'. In other words we learn to prefer something sub-consciously just because we are familiar with it and, as Wexler (p. 159) points out the opposite is also true and 'Dissonance between established beliefs and expectations, on the one hand, and new information input on the other, is seen as creating a drive for its reduction'.

In other forms of experience, we can recall to mind familiarity with places to which we have been days, weeks or years before once we are in the situation or even watching a film about it, which indicates that a present contextual experience can incite apparently long lost memories which illustrates that just below the level of consciousness 
we have archived memories which we can recall to our conscious mind and from which we can learn even though we were not aware of the initial learning experience. Housden (2007) also illustrates this well in her study of reminiscence whereby individuals, especially older ones, are encouraged to recall to their consciousness long-lost memories - and even skills - by being in supportive and often familiar environments.

This implicit knowledge, like explicitly learned knowledge, contributes to the individual's biographical stock of knowledge. It is, therefore, not surprising that it is now widely recognised that we learn from our lives (see Dominice, 2000; Field, 2012, inter alia). Much of what is learned implicitly is brought to our consciousness in narratives - when we tell our story or explain our reasons for our action: it is here when we give meaning to actions and even to life itself (Bruner, 1990).

Returning to my first example, we can see that I had internalised the relationship of the junction in the roads and the location of the hotel unconsciously and that it was only brought into the conscious experience by repeating much of the same experience. Until I had the second experience of standing in the middle of the road, I knew more than I could tell about where the hotel was but in that second experience I brought to my conscious mind those aspects of my previous experience that I had internalised but not learned. In a similar way those craftsmen who were undertaking the same task many times over were no doubt not repeating them precisely each time, but they were reacting to any minor changes in the external situation and adjusting their behaviour just a little in response to them. Their procedures were changing minutely - but they were not always conscious of it: the craftsmen, like me, knew more than we could tell. We were the possessors of tacit knowledge.

Tacit Knowledge: The Greeks knew this form of knowledge as metis: conjectural knowledge. Conjectural knowledge:

$$
\begin{aligned}
& \text { [...] is furtive, discretionary and simultaneous, it spurns } \\
& \text { idealizations and established - representations - it pro- } \\
& \text { vides a contrast to abstract generalizations on every point. } \\
& \text { Where one if hierarchical, the other is organic, indivisible, } \\
& \text { encapsulated in action (Baumard, 1999, p. 54). }
\end{aligned}
$$

A very significant thing about this is that the affect/feelings are learned unconsciously - we feel at ease with the familiar, and so on. Feelings actually underlie a great deal of our motivation to act, but our acquisition of these feelings has been an unconscious process.

This is also what Polanyi (1967) called 'the tacit dimension' in which he (p. 8) suggested that we know more than we can tell. Consciously learned knowledge is explicit but tacit knowledge which is often practical knowledge is much harder to articulate - it is often the outcome of an unconscious awareness acquired during another conscious experience: it is learned because it is at the periphery of our conscious 
Human Learning

awareness. In this sense we can see that being aware of one phenomenon might actually provide the conditions for the acquisition of tacit knowledge about another phenomenon occurring at the same time of which we are barely consciously aware because our awareness is directed elsewhere. Consequently, equating consciousness with awareness is perhaps too simple.

Polanyi (1967, p. 16-7) also throws light on the tacit manner in which we learn aesthetic appreciation and morality. Both, he sees, as the outcome of indwelling, or empathy which occurs because we seek to dwell in the whole phenomena rather than pay attention to their constituent elements. We learn through our feelings! Tacit knowing is unconsciously a combination of knowing what and knowing how and neither is present without the other. At the same time is it not merely the knowing but having confidence that the doing will produce the desired outcomes that demonstrates the outcomes of tacit knowing.

Baumard (1999), however, tends to equate tacit knowing in organisations with a hidden organisational culture which it is impossible to document or patent and which comes from the employees' depth of experience and years of practice. This is the personal dimension of knowing that exists in an organisational culture and which has been internalised as a result of both interaction with other employees and internalising the skills that lead to the practitioner's expertise. However, Baumard points out that this is kept alive by the continuous process of externalisation and internalisation during the functioning of the organisation. However, it is not just the explicit knowledge that circulates during the socialisation process but the tacit knowledge as well. Externalisation in this instance, however, is not articulating but doing which in unconsciously imitated by another and internalised, and so on. Baumard points out that Foucault's (1977) panoptic prison in which 'the potentiality of inspection replaces its deployment' (Baumard, 1999, p. 25) shows how the prisoners internalise tacit knowledge. He points out it is the personal tacit dimension that enables individuals to act beyond the designated framework and gives organisational flexibility. He regards this as the 'reservoir of organisational wisdom that the firm strives either to articulate or to maintain if it is to avoid imitation' (Baumard, 1999, p. 23). The tacit knowledge of its expert employees contribute to its uniqueness - their practical wisdom which is the subjective knowledge that underlies the organisation's culture and is a vital element in organisational functioning as he makes clear.

However, this is not the nature of bureaucracy which demands explicit knowledge, clearly documented, which specifies the procedures of practice. However, work organisations function more like bureaucracies: they want everything to be explicit and documented rather than implicit and subjective. When companies downsize, consequently, they run a major risk of becoming less functional if they dispense with the services of older and more experienced employees, since they are to a 
great extent the carriers of the organisation's culture. Significantly, this tacit knowledge is not something generally acceptable as evidence in our search to understand and neither will research grants be awarded for work based on tacit knowledge, and yet tacit knowing is fundamental to both human and social functioning - it is also quite fundamental to intuition.

Tacit knowledge then is learned unconsciously - it is implicit learning - and stored unconsciously. Some may well be stored in the body, procedural memory - as Archer suggested in the body. But the significant thing about tacit knowledge is that it permeates the whole of our lives.

\section{Concluding Discussion}

From the above discussion it is clear that explicit and implicit learning are probably two different ways of learning and that they relate back to what we internalise as a result of our experiences - the explicit is conscious but the implicit relates to unconscious - or unaware-aspects of experience. But these latter experiences do not seem to involve the mind in the same way as do the former ones. However, all of our sensations are initially bodily sensations and we assume that these sensations are transmitted through the nerve and other bodily systems to the brain: many of which form consciousness and are the mind - but not all of these experiences are registered in the mind. We could say that some of the learning is bodily, or brain, learning as opposed to mind learning - and I do not think that they are repressed experiences.

Now this assumes that the individual person is, in some way, both brain and mind and this clearly constitutes that focus of studies in the philosophy of mind. In my own work (Jarvis, 2012), I have argued that the whole person has a mind which supervenes the brain but which is also part of it - it is the philosophical position of non-reductive monism. Consequently, the person having experiences that are transmitted to the brain - those that register in the mind create consciousness but there are others that the body learns which do not register in the mind (O'Loughlin, 2006) ${ }^{4}$ and so they remain unconscious and implicit.

From the above argument, it can be seen that a great deal of our learning is implicit and a great deal of our behaviour is affected by the unconscious, so that our theories of learning remain incomplete.

Received 03 July 2014 Accepted 10 October 2014

\section{Notes}

1 I have amended the definition just slightly by inserting the natural, as well as the social, as being part of our experience.

Educação \& Realidade, Porto Alegre, v. 40, n. 3, p. 809-823, July/Sept. 2015. 
Human Learning

2 I have tried here to distinguish between what has never entered the conscious mind-bodily learning-from that which has been repressed from the conscious mind and has been the subject of Freudian psychology: the one I have called pre-conscious experiences and the other unconscious experiences. Both forms of 'knowledge' are important in any comprehensive study of human doing.

3 There are major ethical discussions that underlay this research procedure, but now is not the time to pursue them.

4 O'Loughlin's study assumes a monistic interpretation of the world, and it highlights the fact that the body learns, or is sensitised by experiencing the external world.

\section{References}

ALHEIT, Peter et al. The Biographical Approach to European Adult Education. Wien: Verband Wiener Volksbildung, 1995.

ALHEIT, Peter. The Biographical Approach to Lifelong Learning. In: JARVIS, Peter; WATTS, Mary (Ed.). The Routledge International Handbook of Learning, 2012. P. 168-175.

ARCHER, Margaret. Being Human. Cambridge: Cambridge University Press, 2000 .

ARGYRIS, Chris; SCHON, Donald. Theory in Practice: increasing professional effectiveness. San Francisco: Jossey Bass, 1974.

BAUMARD, Philippe. Tacit Knowledge in Organizations. London: Sage, 1999. BERGER, Peter; LUCKMANN, Thomas. The Social Construction of Reality. London: Allen Lane, The Penguin Press, 1966.

BRUNER, Jerome. Acts of Meaning. Cambridge: Harvard University Press, 1990.

CHALMERS, David. The Conscious Mind. Oxford: Oxford University Press, 1996.

DAINTON, Barry. Stream of Consciousness. London: Routledge, 2000.

DAMASIO, Antonio. The Feeling of What Happens. London: Vintage Books, 2000.

DENNETT, Daniel. Content and Consciousness. London: Routledge, 2010.

DOMINICÉ, Pierre. Learning from our Lives. San Francisco: Jossey-Bass, 2000.

FOUCAULT, Michel. Discipline and Punish: the birth of the prison. New York: Pantheon, 1977.

FESER, Edward. Philosophy of Mind. Oxford: Oneworld Publications, 2005.

FIELD, John. Learning from our Lives. In: JARVIS, Peter; WATTS, Mary (Ed.) The Routledge International Handbook of Learning, 2012. P. 176-183.

GLADWELL, Malcolm. Blink: the power of thinking without thinking. London: Penguin, 2005.

HOUSDEN, Sarah. Reminiscence and Lifelong Learning. Leicester: NIACE, 2007.

ILLERIS, Knud. How We Learn. London: Routledge. 2007.

ILLERIS, Knud (Ed.). Contemporary Theories of Learning. London: Routledge, 2009 .

822 Educação \& Realidade, Porto Alegre, v. 40, n. 3, p. 809-823, July/Sept. 2015 
JARVIS, Peter. Adult Learning in the Social Context. London: Croom Helm, 1987.

JARVIS, Peter. Towards a Comprehensive Theory of Human Learning. London: Routledge, 2006.

JARVIS, Peter. Learning to be a Person in Society. London: Routledge, 2009.

JARVIS, Peter. It is the Person who Learns. In: ASPIN, David et al. (Ed.). Second International handbook of Lifelong Learning. Dordrecht: Springer. P. 103-111. v. 1.

MARTON, Ference; BOOTH, Shirley. Learning and Awareness. Mahwah, New Jersey: Lawrence Erlbaum, 1997.

NYIRI, J. C. Tradition and Practical Knowledge. In: NYIRI, J. C.; SMITH, Barry (Ed.). Practical Knowledge: outlines of a theory of traditions and skills. London: Croom Helm, 1988.

OAKESHOTT, Michael. Experience and its Modes. Cambridge: Cambridge University Press, 1933.

O'LOUGHLIN, Marjorie. Embodiment and Education. Dordrecht: Springer, 2006.

POLANYI, Michael. The Tacit Dimension. London: Routledge and Kegan Paul, 1967.

REBER, Arthur. Learning, implicit - entry. In: REBER, Arthur; REBER, Emily (Ed.). Dictionary of Psychology. London: Penguin, 1985.

ROSE, Steven. The 21st Century Brain. London: Jonathan Cape, 2005.

SENNETT, Richard. The Craftsman. London: Allan Lane, the Penguin Press, 2008.

SHELDRAKE, Rupert. The Science Delusion. London: Coronet, 2012.

WEXLER, Bruce. Brain and Culture. Cambridge: MIT Press, 2006.

Peter Jarvis is an Emeritus Professor of Continuing Education at the University of Surrey, England. Research Professor since 2002. Received his Master's Degree in Sociology of Education at the University of Birmingham and his PhD in Sociology of the Professions at the University of Aston. Currently co-editor of the International Journal of Lifelong Education. Has also been writing and lecturing about all aspects of adult education, distance learning and lifelong learning.

E-mail:p.jarvis@surrey.ac.uk 